\title{
PREVENTION OF HAEMORRHAGE FROM THE UMBILICAL CORD
}

BY

\author{
GERALD A. NELIGAN and MARCIA C. SMITH \\ From the Princess Mary Maternity Hospital, Newcastle upon Tyne, and the Department of Child Health in the \\ University of Durham
}

(RECEIVED FOR PUBLICATION MAY 15, 1963)

In December 1962, in the premature nursery of this hospital, a 7-hour-old baby was found dead in a pool of blood which had leaked from the umbilical cord. The baby weighed $4 \mathrm{lb}$. $(1,810 \mathrm{~g}$.) at birth and was under hourly observation by the nursing staff. The cord had been shortened five hours after birth by an experienced staff midwife who had tied a single commercial umbilical tape around it about $1 \frac{1}{4}$ in. $(3 \mathrm{~cm}$.) from the skin margin, and cut it $\frac{1}{2}$ in. $(1 \mathrm{~cm}$.) from the tape. The baby had appeared well, with normal colour, tone and respirations at the age of 6 hours. When he was found dead it was noted that the ligature was still in place, held by a reef knot sufficiently firmly that it could not easily be pulled off, and that the shed blood contained a number of clots. At autopsy no internal abnormality was revealed. Death appeared to have been due to simple exsanguination through an umbilical cord which had been dealt with in accordance with the routine practice of the hospital. It seemed that there was a need for critical reappraisal of this routine practice.

\section{Retrospective Clinical Investigation}

The hospital records over the previous $15 \frac{1}{2}$ years were searched for cases of significant haemorrhage from the cord after birth without evidence of bleeding from other sites: 26 cases of 'early' haemorrhage within the first 24 hours of life, and 10 cases of 'late' haemorrhage after the first 48 hours were found. The distribution of the 'early' cases by years is shown in Fig. 1. The most striking feature is the rise in incidence after the introduction of the 'short cord' technique in the latter half of 1952. The rise was actually more than tenfold, from one case in 9,167 live births $(0 \cdot 1$ per 1,000$)$ between July 1947 and June 1952, to 25 cases in 20,287 live births $(1 \cdot 2$ per 1,000$)$ between January 1953 and December 1962. Also, the six cases that required a blood transfusion, as well as the death, occurred during the second period. These findings might, of course, have been deceptive, attributable to a change in the standard of the routine clinical records and in the indications for blood transfusion, rather than to any real change in incidence-but for the fact that the incidence of 'late' bleeding showed an opposite trend (Fig. 2). The incidence fell from 0.5 per 1,000 live births with one transfusion during the first period, to 0.25 during the second. It seems almost certain that the change in the technique of cord care during the latter part of 1952 produced a true change in the pattern of

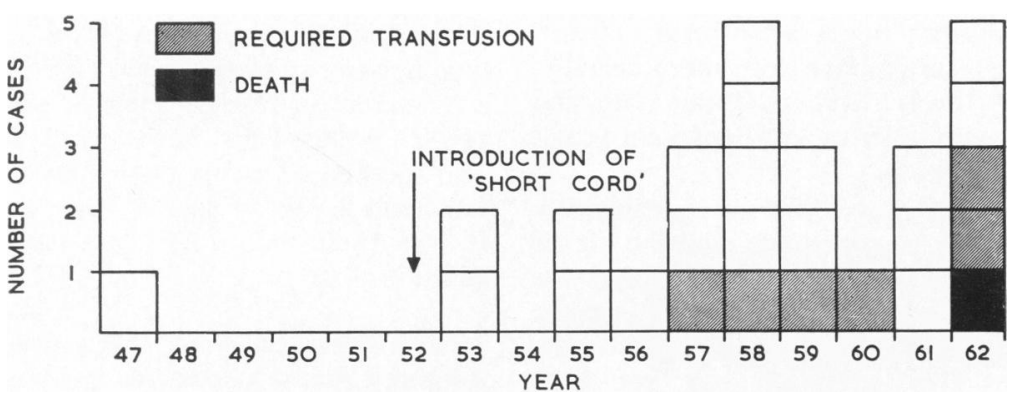

FIG. 1.-The incidence of umbilical haemorrhage within the first 24 hours of life between 1947 and 1962 


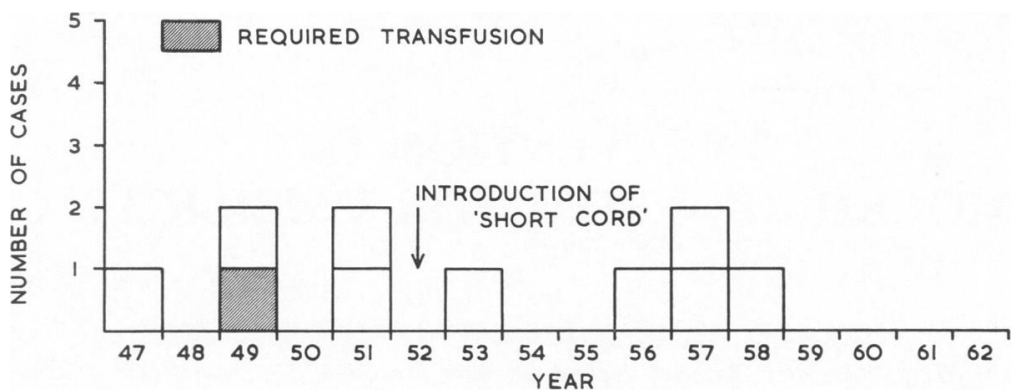

FIG. 2.-The incidence of umbilical haemorrhage after the first 48 hours of life between 1947 and 1962.

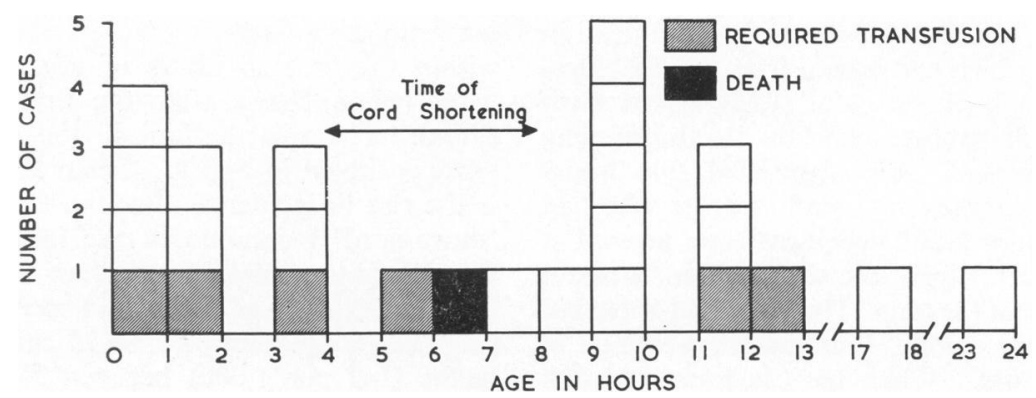

FIG. 3.-The age at which bleeding was discovered, in relation to the age at which the cord was shortened (1953-1962).

umbilical haemorrhage. But the fact that not all instances of 'early' haemorrhage are attributable to shortening of the cord is illustrated by Fig. 3, which shows that 10 of the cases occurred within the first four hours of life before this procedure had been carried out.

The technique of cord care routinely used in the hospital during the first period was the traditional one of applying an absorbent powder and a keyhole linen dressing to the cord stump which was ligated and cut about 6 in. $(15 \mathrm{~cm}$.) from the abdominal wall, with a binder to keep it all in place. During the second period the cord stump was routinely shortened four to eight hours after birth, as described in the fatal case above (or, more usually, cut even shorter). It was then left without a dressing but cleaned daily with ether or, during recent years, $\frac{1}{2} \%$ chlorhexidine in spirit.

The cases of 'late' bleeding are presumably instances of secondary haemorrhage, and the higher incidence when the cord was left long suggests the effect of mechanical factors exerting traction on the gangrenous attachment of the cord stump to the abdominal wall. This condition has not been investigated in any detail.

\section{Laboratory Study of 'Early' Haemorrhage}

The effects of 'early' haemorrhage were far more serious, and it was decided to study its prevention in some detail. It was necessary to find an efficient method of mechanical occlusion that could be relied upon to maintain haemostasis in those instances where the natural mechanisms failed for some reason. This need was all the greater if the advantages that the 'short cord' technique offered in other directions were to be retained, since it seemed clear that this increased the risk of such failure. Simple observation suggested that the method of occlusion used was not often being seriously challenged in its clinical application; it was common to find the tape ligature so loose that it could be lifted off from a shrunken cord stump some hours after it had been applied without that cord having bled at all. This also focused attention on the crucial importance of the natural shrinkage of the cord with drying. It was therefore decided to set up a laboratory study in three parts.

(1) Testing of Tape Ligatures Applied Under Routine Clinical Conditions in Labour Wards. The lengths of cord discarded at the time of shortening 
TAELE 1

LEAKAGE PAST LIGATURE ON ROUTINE SPECIMENS

\begin{tabular}{c|c|c}
$\begin{array}{c}\text { No. of Cords } \\
\text { Tested }\end{array}$ & $\begin{array}{c}\text { No. That } \\
\text { Leaked }\end{array}$ & $\begin{array}{c}\text { Minimum Hydrostatic Pressure } \\
\text { (cm. water) }\end{array}$ \\
\hline 100 & 25 & $\begin{array}{c}\text { Mean 53 } \\
\text { Range 20-120 }\end{array}$ \\
\hline
\end{tabular}

TABLE 2

FOIIR METHODS OF OCCLUSION COMPARED ON FLUSHED CORDS

\begin{tabular}{|c|c|c|}
\hline Method of Occlusion & No. of Tests & No. of Leaks \\
\hline $\begin{array}{ll}1 \text { tape ligature } & \ldots \\
2 \text { tape ligatures } & \ldots \\
\text { Metal clip (Lovsett) } & \ldots \\
\text { Plastic clamp (Hollister) } & \ldots\end{array}$ & $\begin{array}{l}50 \\
50 \\
50 \\
50\end{array}$ & $\begin{array}{r}38 \\
34 \\
10 \\
0\end{array}$ \\
\hline
\end{tabular}

by the nursing staff in the lying-in wards were used for this purpose. A plastic catheter connected to a standard transfusion set was tied into the umbilical vein, and a hydrostatic pressure of $120 \mathrm{~cm}$. of water was applied. If water leaked past the ligatures (of which there were always two, often more), the cord was raised to find the minimum hydrostatic pressure at which leakage persisted. Of the 100 cords tested, leakage occurred in 25 (Table 1).

(2) Comparison of Four Different Methods of Occlusion Subjected to a Standard and Severe Challenge. When the cord is ligated under clinical conditions, variable amounts of clot form in the vein and may modify the effects of the hydrostatic pressure during the above test. For the comparative study, therefore, lengths of cord were obtained in the labour ward and the vein was flushed out with water before clotting could occur. The various methods of occlusion were applied and tested with hydrostatic pressure between six and 24 hours later when considerable shrinkage of the cord had occurred. At least two, and usually all four, of the methods could be applied to different lengths of the same cord, so that they were tested under strictly comparable conditions.

The methods of occlusion compared were: (a) single ligature of commercial umbilical tape, tied as tightly as possible with a reef knot; (b) two such ligatures, about 1 in. $(2 \cdot 5 \mathrm{~cm}$.) apart; (c) metal clip (Lovsett) applied with special crushing pliers; (d) plastic clamp (Hollister) applied with finger pressure. The results are summarized in Table 2.

It is apparent that multiplication of an inefficient method (tape ligature) does not significantly increase its efficiency. With the metal clip, two of the leaks were caused by failure to occlude the vein, as in the case of the ligature, but the remaining eight were due to tearing of the cord and vein during application of the clip. These tears were often inconspicuous and not detected until the leak was revealed by the hydrostatic pressure test. The complete effectiveness of the Hollister plastic clamp was attributable to the fact that it did not tend to tear the cord when first applied, and had a sufficiently elastic compressing action to maintain continuous pressure upon the cord stump during the process of shrinking. This point is illustrated in Fig. 4, where the elastic bending of the jaws when applied to a fresh cord has been demonstrated by substituting a segment of rubber tubing.

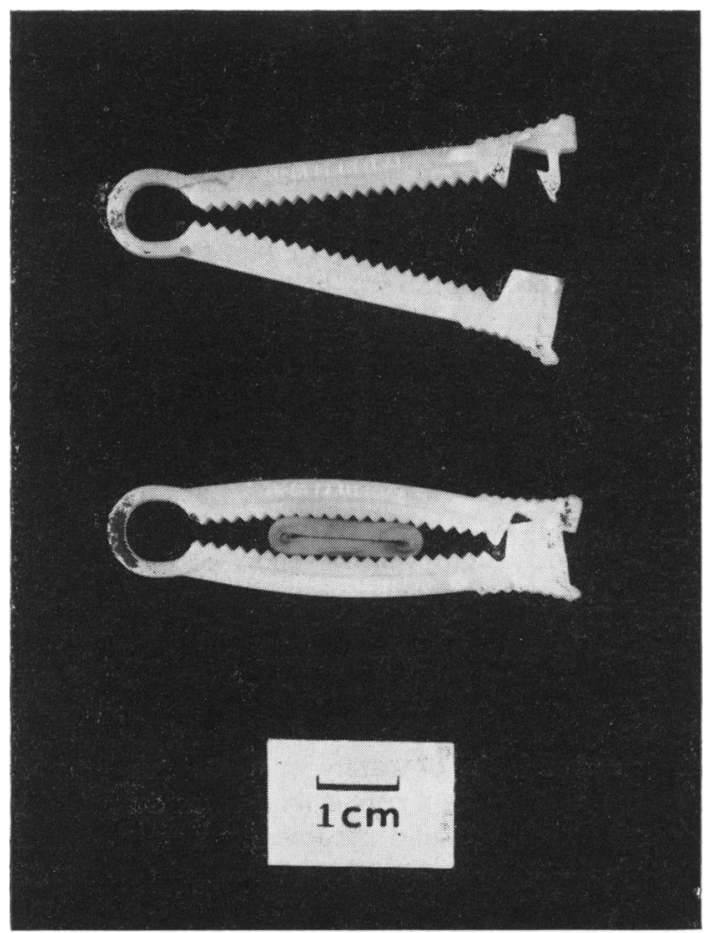

Fig. 4.-Plastic umbilical clamp (Hollister) showing (a) jaws open, disclosing serrated surface and appearance of catch; (b) jaws closed over a piece of rubber tubing, their curve demonstrating the elastic nature of the compressing force.

(3) Measurement of Cord Shrinkage. The volume of fresh segments of cord 4 in. $(10 \mathrm{~cm}$.) long was measured by displacement, and the measurement was repeated after 24,48 and 72 hours of exposure to room air. The eventual length was also measured. The results are summarized in Table 3 .

The very much greater relative decrease in volume 
TABLE 3

MEASUREMENT OF CORD SHRINKAGE

\begin{tabular}{c|c|c|c|c|c|c}
\hline $\begin{array}{c}\text { No. of } \\
\text { Segments }\end{array}$ & \multicolumn{3}{|c|}{$\begin{array}{c}\text { Mean Volume } \\
\text { (ml.) }\end{array}$} & \multicolumn{2}{c}{$\begin{array}{c}\text { Mean Length } \\
\text { (cm.) }\end{array}$} \\
\cline { 2 - 6 } & Fresh & 24 hrs. & 48 hrs. & 72 hrs. & Fresh & $72 \mathrm{hrs.}$ \\
\hline 20 & $7 \cdot 8$ & $2 \cdot 9$ & $1 \cdot 2$ & 0.9 & 10 & $7 \cdot 3$ \\
\hline
\end{tabular}

$(89 \%)$ than in length $(27 \%)$ presumably reflects the magnitude of the decrease in circumference that occurs during shrinkage.

\section{Discussion}

Any mechanical occlusion of the umbilical cord after birth should theoretically be superfluous, since natural mechanisms of haemostasis exist. This fact, so obvious in the young of other mammals, has been confirmed for the human species in studies where the cords of a small number of babies have simply been divided and left in a natural state after delivery (Bernstine, Ludmir and Fritz, 1959). But there are clearly rare instances in which the natural mechanism fails: therefore, if the animal concerned is of sufficient cash value to make an occasional death from early umbilical haemorrhage a matter of some concern, it is customary to use a mechanical method of occlusion to supplement the natural mechanism (Mahaffey and Rossdale, 1959). Death of a baby from this cause must presumably be a very rare event, since we have only been able to find a single case reported in the English literature during the past 30 years (Snelling, 1942). Perhaps the widespread adoption of 'short cord' techniques during recent years may have increased the risk, however.

The ideal of compressing the cord and maintaining continuous pressure during the process of shrinkage has long been advocated. For instance, Gigli (1902) described a sort of safety pin for the purpose. A method of using a rubber band was described by Rothschild (1910), and modifications were reported by Snelling (1942), Salvatore (1957) and Lancaster (1958). Unfortunately, all these methods involve the use of a special instrument to apply the band, and a level of manipulative skill more appropriate to the obstetric surgeon than the midwife. But this simple method of applying elastic compression clearly merits further study.

The standard method of ligating the cord with virtually inelastic tape clearly does not conform with the ideal, and has been demonstrated by this investigation to be extremely ineffective. The metal clip appears to be designed so to crush the cord when it is applied that subsequent shrinkage at that particular point can hardly occur. In our hands this objective was not always achieved, and there was an alarming incidence of damage to the cord, as revealed by our test.

The plastic clamp (Hollister) was chosen for study since it conformed to the ideal requirements, combining simplicity of application with sufficient elasticity in its compressing action. A clinical trial in 1,600 babies had been reported by Kariher and Smith (1961). Our laboratory tests amply confirmed its efficiency, and a clinical trial has been started. It has so far been used on 50 babies with satisfactory results.

The clamp is sterilized by autoclaving at $250^{\circ} \mathrm{F}$. $\left(121^{\circ} \mathrm{C}\right.$.) and is available at the time of delivery. The cord is first clamped with metal haemostats and divided in the usual way. Some minutes later, when convenient, the nurse or doctor applies the plastic clamp across the cord stump just clear of the skin margin, snapping the jaws shut with the thumb and fingers of one hand. The cord is then cut about $\frac{1}{2}$ in. $(1 \cdot 2 \mathrm{~cm}$.) beyond the clamp, leaving this small length of tissue to prevent any risk of the clamp slipping off, and to dry up during the next few hours so as to form an effective haemostatic seal. After 24 hours or so the clamp is removed by cutting through the hinge with a pair of strong scissors or nail-clippers since the catch which holds the jaws together cannot easily be opened again. Removal is desirable to eliminate any risk of traction provoking secondary haemorrhage at the stage of gangrene of the stump: and 24-48 hours is regarded as a more suitable time than the 12 hours recommended by the makers, in view of the results of this retrospective clinical study (Fig. 3). When the clamp is removed the cord remnant is wafer-thin and semi-transparent. It seems that separation occurs earlier than with other methods that have been used.

\section{Summary}

Following the death of a baby from simple umbilical haemorrhage at the age of 7 hours, a retrospective clinical investigation was carried out which showed that the incidence of early haemorrhage has increased since the 'short cord' technique was introduced, and a laboratory investigation showed that under comparable conditions both a tape ligature and a metal clip were less effective and reliable methods of occluding the cord than a plastic clamp (Hollister).

The use of the plastic clamp is described, and a successful clinical trial in 50 babies reported.

We are grateful to all those members of the nursing staff of the hospital whose ready co-operation made this investigation possible: and particularly to Miss E. Storey, 
S.R.N., S.C.M., who brought the plastic clamp (Hollister) to our notice. A supply of the clamps, for use in the laboratory and clinical trial, was made available by Messrs. Charles F. Thackray Limited, of Leeds, who are the British agents for the Hollister Company Inc. of Chicago. During the preparation of this work for publication, M.C.S. was supported by a grant from the Medical Research Trust Fund of the Spastics Society, London.

\section{REFERENCES}

Bernstine, J. B., Ludmir, A. and Fritz, M. (1959). Bacteriologic studies in ligated and nonligated umbilical cords. Amer. J. Obstet. Gynec., 78, 69.
Gigli (1902). Instrument zur Compression der Nabelschnur Mschr. Geburt. Gynäk., 16, 659.

Kariher, D. H. and Smith, T. W. (1961). An improved disposable cord clamp. Obstet. and Gynec., 17, 648 .

Lancaster, Y. (1958). Banding the umbilical cord. Amer. J. Obstet. Gynec., 75, 428 .

Mahaffey, L. W. and Rossdale, P. D. (1959). A convulsive syndrome in newborn foals resembling pulmonary syndrome in the newborn infant. Lancet, 1, 1223.

Rothschild, C. (1910). Ein neues Verfahren der Nabelschnurunterbindung. Gynäk. Rdsch., 4, 148.

Salvatore, J. E. (1957). A new instrument for ligation of the umbilical cord. Amer. J Obstet. Gynec. 74, 1130.

Snelling, C. E. (1942). Hemorrhage in the newborn of septic and traumatic origin and from an improperly tied cord. J. Pediat., 20, 644 . 